\title{
Vision Outcomes and Major Complications after Endovascular Coil Embolization of Ophthalmic Segment Aneurysms
}

\author{
C.R. Durst, R.M. Starke, J. Gaughen, Q. Nguyen, J. Patrie, M.E. Jensen, and A.J. Evans
}

\begin{abstract}
BACKGROUND AND PURPOSE: As aneurysms arising from the ophthalmic segment of the internal carotid artery increase in size, they can compress the optic nerve, prompting patients to present with visual disturbances. The purpose of this article is to describe the clinical and angiographic results with an emphasis on visual outcomes following the endovascular treatment of ophthalmic segment ICA aneurysms.
\end{abstract}

MATERIALS AND METHODS: The records of 1254 patients who presented for endovascular treatment of a cerebral aneurysm were retrospectively reviewed to identify 65 consecutive patients who underwent coil embolization of an ophthalmic segment ICA aneurysm. The clinical records, treatment reports, and imaging were reviewed with a focus on visual outcomes.

RESULTS: Twenty-two of the 65 patients (34\%) who presented for treatment of an ophthalmic aneurysm reported a visual disturbance at presentation. Fifteen of the 22 patients $(68 \%)$ experienced an improvement in their symptoms after treatment. Overall, patients with visual symptoms were significantly more likely to benefit from treatment than to have a decline in vision $(P=.03)$. The overall morbidity was $4 \%$, and mortality was $0 \%$. The retreatment rate was high at $30 \%$, though this was disproportionately weighted by an $86 \%$ retreatment rate in patients with ruptured aneurysms.

CONCLUSIONS: Patients with visual symptoms attributable to ophthalmic segment ICA aneurysms undergoing endovascular coil embolization were statistically more likely to experience an improvement in their vision than to have worsening or unchanged vision. Coiling was associated with a low morbidity rate, though an elevated retreatment rate.

A neurysms arising from the ophthalmic segment of the internal carotid artery account for approximately $5 \%$ of all intracranial aneurysms. ${ }^{1,2}$ As these aneurysms increase in size, they can compress the optic nerve, prompting the patient to present with visual disturbances, often involving the inferior and/or nasal fields first. ${ }^{2,3}$ Both surgical and endovascular treatment of these aneurysms have shown the potential to improve visual disturbances if occurring early. ${ }^{2,4-11}$ However, treatment of these aneurysms is not without its own set of inherent risks. Retinal artery

Received February 19, 2014; accepted after revision April 28.

From the Departments of Radiology and Medical Imaging (C.R.D., J.G., M.E.J., A.J.E.), Neurosurgery (R.M.S.), and Public Health Services (J.P.), University of Virginia, Charlottesville, Virginia; and Department of Radiology (Q.N.), Beth Israel Deaconess Medical Center, Boston, Massachusetts.

This work was funded in its entirety by the University of Virginia Department of Radiology.

Paper previously presented at: Annual Meeting of the American Society of Neuroradiology, May 18-23, 2013; San Diego, California.

Please address correspondence to Christopher Durst, MD, University of Virginia Health Systems, Department of Radiology, Neuroradiology Division, PO Box 800170 (FedEx:1215 Lee St-New Hospital), Charlottesville, VA 22908; e-mail: cdurst@virginia.edu

http://dx.doi.org/10.3174/ajnr.A4032 occlusion or delayed optic ischemia may occur after either surgical or endovascular repair. ${ }^{12-14}$ A review of recent surgical literature suggests a permanent morbidity ranging from 3\% to $38 \%$ following treatment of an ophthalmic segment ICA aneurysm. ${ }^{3,5,6,10,15-18}$ This morbidity includes a risk of new or worsened visual disturbance in $2 \%-30 \%$ of surgically treated patients and $3 \%-8 \%$ of endovascularly treated patients. ${ }^{3,5,6,15,16}$

This article assesses the angiographic and clinical outcomes of 65 consecutive patients who presented for initial treatment of an ophthalmic segment ICA aneurysm via an endovascular approach. Our goal is to describe the clinical and angiographic outcomes with an emphasis on visual outcomes following the endovascular treatment of ophthalmic segment aneurysms.

\section{MATERIALS AND METHODS Study Design}

Under the auspices of the institutional review board, the records of 1254 patients who presented for treatment of a cerebral aneurysm between October 2001 and April 2009 were retrospectively reviewed. For the purposes of this article, only ophthalmic segment aneurysms arising from the dorsal internal carotid artery at or immediately adjacent to the origin of the ophthalmic artery 


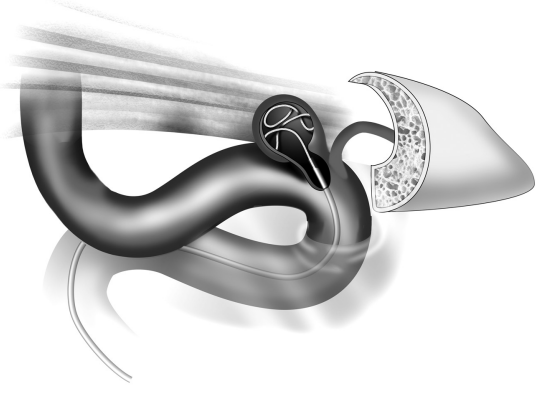

FIG 1. Endovascular coil embolization of an ophthalmic segment aneurysm.

were included, in keeping with the definition by Day. ${ }^{2}$ From our cohort, we identified 65 consecutive patients (5.2\%) who presented for initial endovascular treatment of an ophthalmic segment aneurysm. Medical and radiographic records were independently reviewed by a member of the research team who did not participate in the treatment of any of the included patients. Demographics, details of treatments, effects of treatments, results of follow-up procedures, and complications were recorded.

\section{Interventional Procedures}

All procedures were performed under the care of 1 of 3 neurointerventional surgeons. Endovascular intervention was performed by using a biplane flat panel digital subtraction unit with the patient under general anesthesia. All patients were treated with a bolus of heparin at the beginning of the procedure to reach an activated clotting time of 250-300 seconds. In standard fashion, a guiding catheter was placed in the internal carotid artery, and diagnostic cerebral angiography was performed. Working projections were obtained, the aneurysm was measured, and under roadmap guidance, a microcatheter was placed into the aneurysm sac (Fig 1). Adjunct treatment measures, such as stent-assistance, dual-catheter technique, or balloon remodeling, were performed at the operator's discretion, as noted in the "Results" section. Immediate postprocedural DSA confirmed the occlusion status of the aneurysm and allowed evaluation of parent vessel patency and thromboembolic procedural complications.

\section{Imaging Assessment}

Imaging outcomes were recorded for each case. Immediate treatment outcomes were documented in all cases via digital subtraction angiography in 2 planes. At discharge, patients were scheduled for 6- and 12-month angiographic follow-up with the intent to image via CTA, MRA, or additional DSA studies at 24 months. Long-term follow-up imaging analysis was limited to those patients with at least 12 months' follow-up. The follow-up imaging was evaluated for stability, recurrence, or progressive/delayed occlusion of the aneurysm. In cases of recurrent or residual aneurysms, the remnant was classified according to the Raymond classification scale. ${ }^{19}$

\section{Clinical Assessment}

Through a review of the medical records, the clinical presentation and outcomes were recorded for each patient. Complete neurologic examinations were available for each patient. Visual assess- ment was performed by a neuro-ophthalmologist, neurologist, neurosurgeon, or neurointerventional surgeon. In patients with visual disturbances believed likely to be related to their ophthalmic segment ICA aneurysms, the preprocedural visual disturbance was recorded and compared with their postprocedural evaluation to assess stability, improvement, or deterioration. Major complications were classified as any hemorrhage, clinically significant infarction, or dissection that was directly related to the procedure, as determined by consensus between the neurointerventionalist and the neurosurgeon or neurologist who provided concurrent care to the patient.

\section{Statistical Analysis}

Data are presented as mean and range for continuous variables and as frequency for categoric variables. Statistical analyses of categoric variables were performed by using the $\chi^{2}$ and Fisher exact tests and the Mantel-Haenszel test for linear association, and comparison of means was performed by using the Student $t$ test and Wilcoxon rank sum test as appropriate. Univariate analysis was used to test covariates predictive of the following dependent variables: treatment-related complications, retreatment, and unfavorable visual outcome (decreased visual function or increased visual pain). Additionally, stable or worse visual outcome was defined as those patients with increased visual pain or decreased neurologic function or no improvement in baseline visual pain or neurologic dysfunction. Only 1 patient had improvement in visual dysfunction but increased visual pain and was categorized as an unfavorable visual outcome. No patients had decreased visual pain but decreased visual function. Interaction and confounding were assessed through stratification and relevant expansion covariates. Independent factors predictive of the 5 dependent variables in univariate analysis $(P<.20)$ were entered into 5 separate multivariate logistic regression analyses. $P$ values $\leq .05$ were considered statistically significant. ${ }^{20}$ Statistical analysis was performed with STATA 10.0 (StataCorp, College Station, Texas).

\section{RESULTS}

\section{Patient Demographics and Aneurysm Characteristics}

Of the 65 patients included in this study, 57 (87.7\%) were women (Table 1). The average age was 56 years. Twenty-two of the 65 patients presented with a visual disturbance (Table 2). Eleven patients presented after rupture of the aneurysm. Almost half of the patients were hypertensive $(n=31)$.

The average diameter of the aneurysms was $8.4 \mathrm{~mm}$, with the difference between ruptured aneurysm diameter $(10.6 \mathrm{~mm})$ and unruptured aneurysm diameter $(7.9 \mathrm{~mm})$ approaching significance $(P=.086)$. Aneurysms causing a visual disturbance $(9.1$ $\mathrm{mm}$ ) tended to be larger than those that did not $(8.1 \mathrm{~mm})$, though this was not statistically significant $(P=.18)$.

Most patients ( $n=52,80 \%$ ) were treated by coil embolization alone. Four patients $(6 \%)$ were treated by using balloon assistance. Nine (14\%) underwent stent-assisted coil embolization.

\section{Visual Outcomes}

Twenty-two of the 53 patients (42\%) who presented for elective treatment of an unruptured ophthalmic segment ICA aneurysm 
Table 1: Patient demographics and aneurysm characteristics with breakdown of the characteristics according to the presence/absence of a visual disturbance at presentation

\begin{tabular}{|c|c|c|c|c|}
\hline Variable & Total & $\begin{array}{c}\text { Visual } \\
\text { Disturbance }\end{array}$ & $\begin{array}{l}\text { No Visual } \\
\text { Disturbance }\end{array}$ & $P$ Value \\
\hline Total & 65 & $22(34)$ & $43(66)$ & \\
\hline \multicolumn{5}{|l|}{ Demographics } \\
\hline Age (yr) (average) (range) & $56 \pm 11.4(26-78)$ & $55 \pm 14(26-70)$ & $56.5 \pm 10.1(38-78)$ & 656 \\
\hline Sex & & & & 1.000 \\
\hline Female (No.) (\%) & $57(88)$ & $19(86)$ & $38(88)$ & \\
\hline Male (No.) $(\%)$ & $8(12)$ & $3(14)$ & $5(12)$ & \\
\hline \multicolumn{5}{|l|}{$\begin{array}{l}\text { Presentation (patient may be included in } \\
\text { multiple categories) }\end{array}$} \\
\hline Visual disturbance (No.) (\%) & $22(20)$ & $22(100)$ & $0(0)$ & \\
\hline Headache (without SAH) (No.) (\%) & $24(37)$ & $9(41)$ & $15(35)$ & \\
\hline Incidental (No.) (\%) & $15(23)$ & $0(0)$ & $13(30)$ & \\
\hline Hemorrhage (No.) (\%) & $12(18)$ & $1(5)$ & $10(23)$ & \\
\hline Other neurologic sequelae (No.) (\%) & $11(17)$ & $2(10)$ & $9(21)$ & \\
\hline Hypertension & & & & .800 \\
\hline Yes (No.) (\%) & $31(48)$ & $11(50)$ & $20(47)$ & \\
\hline No (No.) (\%) & $34(52)$ & $11(50)$ & $23(53)$ & \\
\hline \multicolumn{5}{|l|}{ Aneurysm characteristics } \\
\hline Diameter (mm) (average) (range) & $8.4 \pm 4.6(2-20)$ & $9.1 \pm 5.5(2-20)$ & $8.1 \pm 4.1(2.2-19)$ & .476 \\
\hline Volume $\left(\mathrm{mm}^{3}\right)$ (average) (range) & $417 \pm 681(3-2724)$ & $565 \pm 850(3.7-2724)$ & $341 \pm 573(3-2544)$ & .273 \\
\hline Neck width (mm) (average) (range) & $3.9 \pm 1.5(1.3-8)$ & $3.9 \pm 1.9(1.5-7.4)$ & $3.9 \pm 1.3(1.3-8)$ & .905 \\
\hline Dome-to-neck ratio (average) (range) & $2.1 \pm 0.8(1-6)$ & $2.3 \pm 1(1.2-6)$ & $2.1 \pm 0.7(1-3.8)$ & .320 \\
\hline Sidedness & & & & .791 \\
\hline Left (No.) (\%) & $39(60)$ & $14(64)$ & $25(58)$ & \\
\hline Right (No.) (\%) & $26(40)$ & $8(36)$ & $18(42)$ & \\
\hline
\end{tabular}

Table 2: Visual disturbances prompting 22 patients to present for evaluation ${ }^{\mathrm{a}}$

\begin{tabular}{lc}
\hline Presenting Symptom & No. of Patients (\%) \\
\hline Change in visual acuity & $16(73)$ \\
Visual field defect & $5(23)$ \\
Ophthalmoplegia & $4(18)$ \\
Diplopia & $2(9)$ \\
\hline
\end{tabular}

Patients may have presented with $>1$ symptom.

were found to have a visual disturbance at presentation. A change in visual acuity was the most common symptom (Table 1 ). Seven of the 22 patients (32\%) were evaluated by an ophthalmologist. The average magnification requirement for patients seen by an ophthalmologist was $10.6 \pm 6.1$. Four of the 7 patients $(57 \%)$ had a visual field deficit, 2 with a central deficit, 1 with a nasal field deficit, and 1 with a left superior homonymous deficit. Three of the 7 patients (43\%) had evidence of optic nerve atrophy. Patients with visual disturbances were more likely to have a larger aneurysm diameter, though this was not statistically significant (Table 1).

Following treatment, patients in this study were much more likely to have an improvement in their visual symptoms than to develop a new or worsening visual disturbance $(P=.03)$. Fifteen of the 22 patients $(68 \%)$ experienced an improvement in their ophthalmologic examinations as measured by a combination of confrontational testing and a Snellen chart. Five patients $(23 \%)$ had no change in their visual symptoms. Three of these 5 patients $(60 \%)$ had documented optic nerve atrophy on their ophthalmologic examination. Two patients (9\%) experienced a decline in their visual acuity. One patient (2\%) developed a new decline in visual acuity after treatment.

Patients whose visual disturbance improved following endovascular coiling of their ophthalmic segment aneurysm tended to
Table 3: Aneurysm characteristics among patients who either presented with a visual disturbance or developed one after treatment ${ }^{\mathrm{a}}$

\begin{tabular}{lccc}
\hline \multicolumn{1}{c}{ Variable } & $\begin{array}{c}\text { Improved } \\
(\boldsymbol{n}=15)\end{array}$ & $\begin{array}{c}\text { Not } \\
\text { Improved or } \\
\text { Worse }(\boldsymbol{n}=\mathbf{8})\end{array}$ & $\boldsymbol{P}$ Value \\
\hline Aneurysm size & $7.7 \pm 5.2$ & $11.9 \pm 5.1$ & .082 \\
Neck diameter & $3.2 \pm 1.5$ & $5.3 \pm 1.6$ & .009 \\
Dome-to-neck ratio & $2.09 \pm 1.1$ & $2.2 \pm 0.7$ & .738 \\
Packing attenuation & $28.6 \pm 13.7$ & $27.1 \pm 10.1$ & .773 \\
Requiring retreatment & $2(13 \%)$ & $4(50 \%)$ & .131 \\
\hline
\end{tabular}

${ }^{a}$ There are 23 total patients because 1 patient developed a new visual disturbance after treatment

have smaller aneurysms with a smaller neck than those who remained stable or whose vision deteriorated (Table 3).

\section{Complications}

Sixteen patients required $\geq 1$ retreatment, resulting in 91 total treatments of the 65 unique aneurysms (Table 4). The overall morbidity from the 91 treatments was $4 \%$ ( 4 cases). There were no deaths. Three of the complications occurred in the 81 treatments of unruptured aneurysms (3\%). In 1 of these cases, the patient developed hydrocephalus despite the lack of hemorrhage, requiring a shunt. Two patients presented with an acute infarction $>7$ days after treatment. Of the 12 treatments of ruptured aneurysms, there was 1 complication (8\%). In this case, the patient experienced a postprocedural infarction due to hypoperfusion.

Univariate predictors of treatment-related complications $(P<$ $.20)$ included the presence of subarachnoid hemorrhage $(P=.105)$, no visual disturbance on presentation $(P=.102)$, a history of hypertension $(P=.037)$, packing attenuation of $<22 \%(P=.158)$, the presence of a stent $(P=.171)$, the use of clopidogrel $(0.146)$, and the presence of residual filling of the aneurysm at the end of the procedure $(P=.049)$. A multivariate analysis showed that patients with 
ruptured aneurysms were 5.8 times more likely to experience a major complication (95\% CI, 1.02-33.03; $P=.047$ ). In addition, those patients with hypertension were 5.2 time more likely to experience a complication (95\% CI, 1.08-24.93; $P=.039$ ).

\section{Imaging Outcomes}

Of the 65 aneurysms, 35 (55\%) were completely occluded at the end of the procedure. Thirty of the 53 unruptured aneurysms $(58 \%)$ and 5 of the $12(42 \%)$ ruptured aneurysms were completely occluded at the end of the case (Table 4). At 12 months' follow-up, 2 of the 26 ( $8 \%$ ) patients who had some residual filling at the end of the procedure demonstrated delayed occlusion of the aneurysm.

Long-term outcomes ( $\geq 12$ months) were available for 53 (82\%) patients. Overall, $16(30 \%)$ of the patients with at least 12 months' follow-up required retreatment, including 10 of 46 (22\%) patients treated electively and 6 of $7(86 \%)$ patients treated after a subarachnoid hemorrhage. Univariate predictors of retreatment $(P<.20)$ included ruptured aneurysm $(P=.002)$, increasing Hunt and Hess scale score $(P=.013)$, family history of aneurysms $(P=.144)$, aneurysms on the left $(P=.039)$, increasing maximum aneurysm diameter $(P<.001)$, increasing maximum neck diameter $(P=.008)$, increasing neck-to-dome ratio $(P=.090)$, decreasing packing attenuation $(P=.034)$, and packing attenuation of $\angle 22 \%(P=.003)$. The multivariate analysis demonstrated that those with a ruptured aneurysm were 44.2 times more likely to have a recurrence $(95 \% \mathrm{CI}, 3.80-514.04 ; P=$ $.002)$. In addition, the diameter of the aneurysm was predictive of recurrence $(\mathrm{OR}=1.36$; 95\% $\mathrm{CI}, 1.10-1.69 ; P=.005)$. In particular, aneurysms of $>10 \mathrm{~mm}$ were at greater risk of recurrence $(\mathrm{OR}=12.64 ; 95 \% \mathrm{CI}, 2.05-78.06 ; P=.022)$. Finally, aneurysms with a packing attenuation of $\geq 22 \%$ were $84 \%$ less likely to recur $(\mathrm{OR}=0.16$; 95\% CI, 0.03-0.96; $P=.045)$.

\section{DISCUSSION}

Patients who present with a visual disturbance attributable to an ophthalmic segment ICA aneurysm can expect further deterioration of their vision if the aneurysm is left untreated. ${ }^{7,21}$ Once treated, either endovascularly or surgically, a patient's vision would be expected to improve. Suction decompression during surgery relieves the direct mass effect of the aneurysm on the optic apparatus. The means by which endovascular treatment improves visual outcomes is not well-understood. One possibility is that thrombosis after coil embolization may relieve the pulsatile pressure on the optic nerve. ${ }^{22}$ A review of prior literature suggests that $49 \%$ of patients treated endovascularly ${ }^{3-6,12,23}$ and $63 \%$ of patients treated surgically $y^{2,5,8-11,23-25}$ could be expected to experience improvement in their visual symptoms (Tables 5 and 6). Treatment, of course, is not without risk. If one looked broadly at the literature and combined data that included ruptured and unruptured ophthalmic segment ICA aneurysms, approximately $6 \%$ of patients treated endovascularly ${ }^{3-5,15,16,18,23}$ and $9 \%$ of patients treated surgically $2,3,5,6,9-11,15,17,18,23-25$ may develop a new visual disturbance or experience worsening of their visual symptoms. In

\footnotetext{
${ }^{a}$ Retreatment-versus-progressive occlusion/unchanged
}

Table 5: Visual outcomes after endovascular treatment of aneurysms affecting the visual pathway

\begin{tabular}{|c|c|c|c|c|c|c|}
\hline Reference & $\begin{array}{c}\text { Preoperative Visual } \\
\text { Disturbance } \\
\text { (No.) }\end{array}$ & $\begin{array}{c}\text { Postoperative } \\
\text { Improvement } \\
\text { (No.) }\end{array}$ & $\begin{array}{c}\text { Visual } \\
\text { Improvement } \\
(\%)\end{array}$ & $\begin{array}{c}\text { Total } \\
\text { Aneurysms } \\
\text { (No.) }\end{array}$ & $\begin{array}{c}\text { New or Worsening } \\
\text { Visual Disturbance } \\
(\%)\end{array}$ & $\begin{array}{c}\text { Visual } \\
\text { Decline } \\
(\%)\end{array}$ \\
\hline Our data & 22 & 15 & 68 & 65 & 3 & 5 \\
\hline Andaluz et al, $2005^{15}$ & & & & 17 & 1 & 6 \\
\hline Heran et al, $2007^{4}$ & 16 & 6 & 38 & 16 & 6 & 38 \\
\hline Hoh et al, $2001^{5}$ & 4 & 3 & 75 & 57 & 2 & 4 \\
\hline lihara et al, $2003^{16}$ & & & & 77 & 2 & 3 \\
\hline Kanagalingam et al, $2012^{3}$ & & & & 22 & 1 & 5 \\
\hline Schuss et al, $2011^{23}$ & 8 & 3 & 38 & 8 & 2 & 25 \\
\hline Sherif et al, $2009^{18}$ & & & & 38 & 2 & 5 \\
\hline Vargas et al, 19947 & 19 & 7 & 37 & 19 & 1 & 5 \\
\hline Yadla et al, $2011^{6}$ & 10 & 5 & 50 & & & \\
\hline Total & 79 & 39 & 49 & 319 & 20 & 6 \\
\hline
\end{tabular}


Table 6: Visual outcomes after surgical treatment of aneurysms affecting the visual pathway

\begin{tabular}{|c|c|c|c|c|c|c|}
\hline Reference & $\begin{array}{l}\text { Preoperative Visual } \\
\text { Disturbance } \\
\text { (No.) }\end{array}$ & $\begin{array}{l}\text { Postoperative } \\
\text { Improvement } \\
\text { (No.) }\end{array}$ & $\begin{array}{c}\text { Visual } \\
\text { Improvement } \\
(\%)\end{array}$ & $\begin{array}{l}\text { Total } \\
\text { Aneurysms } \\
\text { (No.) }\end{array}$ & $\begin{array}{c}\text { New or Worsening } \\
\text { Visual Disturbance } \\
(\%)\end{array}$ & $\begin{array}{c}\text { Visual } \\
\text { Decline } \\
(\%)\end{array}$ \\
\hline Andaluz et al, $2005^{15}$ & & & & 65 & 4 & 6 \\
\hline Date et al, $1998^{8}$ & 6 & 4 & 67 & & & \\
\hline Day, $1990^{2}$ & 23 & 17 & 74 & 54 & 6 & 11 \\
\hline Drake et al, $1968^{\circ}$ & 32 & 15 & 47 & 100 & 5 & 5 \\
\hline Ferguson et al, 1981" & 29 & 15 & 52 & 29 & 5 & 17 \\
\hline Fulkerson et al, $2009^{17}$ & & & & 118 & 7 & 6 \\
\hline Hoh et al, $2001^{5}$ & 12 & 8 & 67 & 187 & 5 & 3 \\
\hline Kanagalingam et al, $2012^{3}$ & & & & 69 & 21 & 30 \\
\hline Mattingly et al, $2013^{24}$ & 14 & 11 & 79 & 18 & 4 & 22 \\
\hline Nanda and Javalkar, $2011^{10}$ & 15 & 10 & 67 & 80 & 7 & 9 \\
\hline Park et al, $2009^{30}$ & 10 & 8 & 80 & 10 & 0 & 0 \\
\hline Schuss et al, $2011^{23}$ & 12 & 9 & 75 & 12 & 2 & 17 \\
\hline Sherif et al, $2009^{18}$ & & & & 23 & 1 & 4 \\
\hline Yadla et al, $2011^{6}$ & & & & 23 & 2 & 9 \\
\hline Total & 153 & 97 & 63 & 788 & 69 & 9 \\
\hline
\end{tabular}

our series, $68 \%$ of patients treated endovascularly experienced an improvement in their visual symptoms. Two of 53 (4\%) patients treated electively and 1 of $12(8 \%)$ treated after a rupture developed a new or worse visual disturbance. Of note, 2 of the 3 patients who developed a new or worse visual disturbance were found to have a recurrence of their aneurysm, which may have contributed to their worsening symptoms. ${ }^{14}$ This information can help neurointerventional surgeons better inform patients about the risks and benefits of the endovascular treatment of ophthalmic segment aneurysms.

A potential benefit in treating ophthalmic segment ICA aneurysms via endovascular coil embolization is a relative reduction in overall morbidity compared with open surgery. Three of 79 elective treatments (4\%) in this study resulted in permanent morbidity. Two of the patients experienced an infarction, 1 of which was clearly related to the procedure and the other most likely not because emboli were found in multiple vascular territories. The third patient developed hydrocephalus after treatment. Overall, the $4 \%$ rate of complications reported here is within the range of $0.8 \%-18 \%$, with an average of $4 \%$ reported for 691 endovascularly treated ophthalmic segment ICA aneurysms in the literature. $^{3-7,15,16,18,19,23,25-28}$ This complication rate is considerably less than those reported for the open treatment of ophthalmic segment aneurysms. Even with the development of microsurgical techniques, the reported morbidity in the literature during the past 5 years ranged from $9 \%$ to $39 \%$, with an average of $21 \%$ for 381 patients. ${ }^{3,6,10,17,18,23,29}$ Although this study does not directly compare endovascular and open surgical techniques, the studies that have made this comparison have demonstrated an endovascular complication rate ranging from $0 \%$ to $18 \%$, with an average of $4.5 \%$ for 358 aneurysms, while the surgical complication rate ranged from $3.7 \%$ to $27.5 \%$ with an average of $11.2 \%$ for 402 aneurysms. ${ }^{3,5,15,16}$

Of the 65 unruptured aneurysms, 55\% were occluded primarily. This finding is similar to the $47 \%$ primary occlusion rate of 523 cumulative aneurysms treated endovascularly reported in the literature..$^{3-6,25-27,28}$ In the 30 patients who presented for at least 12 months of follow-up, 2 aneurysms (7\%) that were not completely occluded at initial coiling progressed to complete occlu- sion at their follow-up examinations. The appearance of $64 \%$ of the aneurysms at follow-up was unchanged.

Overall, 30\% of the aneurysms reported in this study required retreatment. This retreatment rate is skewed by the $86 \%$ retreatment rate in ruptured aneurysms compared with the $22 \%$ retreatment rate in unruptured aneurysms $(P=.002)$. At our institution, our intent when treating ruptured aneurysms is to first protect the dome and any suspicious components of the aneurysm that may represent a point of rupture, such as a bleb or pseudoaneurysm. A broad review of the literature suggests a $20 \%$ recurrence rate with a range of $9 \%$ $53 \%$ in 503 aneurysms. ${ }^{3-6,18,25-27,28}$ As expected, the retreatment rate after open clipping is significantly less than that after endovascular coil embolization. In a direct comparison of endovascular and open treatment of ophthalmic segment aneurysms, Sherif et $\mathrm{al}^{18}$ and Yadla et $\mathrm{al}^{6}$ reported a combined $4 \%$ retreatment rate after open clipping.

This study is limited by the retrospective nature and all of the biases imparted therein. Formal neuro-ophthalmologic evaluation was not available for all patients. In each of these cases, a visual assessment was available from a neurologist, neurosurgeon, or the interventional neuroradiologist. In cases of opposition testing, small defects may have been missed by either the patient or the physician. Given the retrospective nature of the study, the quality of the data is dependent on the clinical skill and reporting practices of multiple physicians. Thus, interpretation of improvement or worsening in visual symptoms at follow-up in patients not seen by an ophthalmologist is essentially subjective and dependent on the thoroughness of the documentation.

\section{CONCLUSIONS}

Patients with visual symptoms attributable to ophthalmic segment ICA aneurysms having undergone endovascular coil embolization were statistically more likely to experience an improvement in their vision than to have worsening or unchanged vision. Coiling was associated with a low morbidity rate (4\%). However, the retreatment rate following coiling was elevated (30\%).

Disclosures: John Gaughen-UNRELATED: Consultancy: Covidien, MicroVention, Stryker. Mary E. Jensen-UNRELATED: Payment for Lectures (including service on Speakers Bureaus): Speakers Bureau for Stryker Neurovascular; training lectures for Covidien. Avery J. Evans-UNRELATED: Consultancy: Stryker, Covidien, Grants/ 
Grants Pending: Stryker, Patents (planned, pending or issued): US Patent Office, Mod Med Inc, Royalties: Cook, CareFusion.

\section{REFERENCES}

1. Locksley HB. Natural history of subarachnoid hemorrhage, intracranial aneurysms and arteriovenous malformations: based on 6368 cases in the cooperative study. J Neurosurg 1966;25:219-39

2. Day AL. Aneurysms of the ophthalmic segment: a clinical and anatomical analysis. J Neurosurg 1990;72:677-91

3. Kanagalingam S, Gailloud P, Tamargo RJ, et al. Visual sequelae after consensus-based treatment of ophthalmic artery segment aneurysms: the Johns Hopkins experience. J Neuroophthalmol 2012;32:27-32

4. Heran NS, Song JK, Kupersmith MJ, et al. Large ophthalmic segment aneurysms with anterior optic pathway compression: assessment of anatomical and visual outcomes after endosaccular coil therapy. J Neurosurg 2007;106:968-75

5. Hoh BL, Carter BS, Budzik RF, et al. Results after surgical and endovascular treatment of paraclinoid aneurysms by a combined neurovascular team. Neurosurgery 2001;48:78-89, discussion 89-90

6. Yadla S, Campbell PG, Grobelny B, et al. Open and endovascular treatment of unruptured carotid-ophthalmic aneurysms: clinical and radiographic outcomes. Neurosurgery 2011;68:1434-43, discussion 1443

7. Vargas ME, Kupersmith MJ, Setton A, et al. Endovascular treatment of giant aneurysms which cause visual loss. Ophthalmology 1994;101:1091-98

8. Date I, Asari S, Ohmoto T. Cerebral aneurysms causing visual symptoms: their features and surgical outcome. Clin Neurol Neurosurg 1998;100:259-67

9. Drake CG, Vanderlinden RG, Amacher AL. Carotid-ophthalmic aneurysms. J Neurosurg 1968;29:24-31

10. Nanda A, Javalkar V. Microneurosurgical management of ophthalmic segment of the internal carotid artery aneurysms: single-surgeon operative experience from Louisiana State University, Shreveport. Neurosurgery 2011;68:355-70, discussion 370-71

11. Ferguson GG, Drake CG. Carotid-ophthalmic aneurysms: visual abnormalities in 32 patients and the results of treatment. Surg Neurol 1981;16:1-8

12. Turner RD, Byrne JV, Kelly ME, et al. Delayed visual deficits and monocular blindness after endovascular treatment of large and giant paraophthalmic aneurysms. Neurosurgery 2008;63:469-74, discussion $474-75$

13. Castillo B Jr, De Alba F, Thornton J, et al. Retinal artery occlusion following coil embolization of carotid-ophthalmic aneurysms. Arch Ophthalmol 2000;118:851-52

14. Schmidt GW, Oster SF, Golnik KC, et al. Isolated progressive visual loss after coiling of paraclinoid aneurysms. AJNR Am J Neuroradiol 2007;28:1882-89

15. Andaluz N, Beretta F, Keller JT, et al. Aneurysms of the ophthalmic (C6) segment of the internal carotid artery: clinical experience, treatment options, and strategies (Part 2). Neurosurg Q 2005;15:91-102

16. Iihara K, Murao K, Sakai N, et al. Unruptured paraclinoid aneurysms: a management strategy. J Neurosurg 2003;99:241-47

17. Fulkerson DH, Horner TG, Payner TD, et al. Endovascular retrograde suction decompression as an adjunct to surgical treatment of ophthalmic aneurysms: analysis of risks and clinical outcomes. Neurosurgery 2009;64:ons107-111, discussion ons111-12

18. Sherif C, Gruber A, Dorfer C, et al. Ruptured carotid artery aneurysms of the ophthalmic (C6) segment: clinical and angiographic long term follow-up of a multidisciplinary management strategy. J Neurol Neurosurg Psychiatry 2009;80:1261-67

19. Roy D, Raymond J, Bouthillier A, et al. Endovascular treatment of ophthalmic segment aneurysms with Guglielmi detachable coils. AJNR Am J Neuroradiol 1997;18:1207-15

20. Altman DG. Practical Statistics for Medical Research. Boca Raton: Chapman \& Hall/CRC; 1999

21. Peiris JB, Ross Russell RW. Giant aneurysms of the carotid system presenting as visual field defect. J Neurol Neurosurg Psychiatry 1980;43:1053-64

22. Kazekawa K, Tsutsumi M, Aikawa H, et al. Internal carotid aneurysms presenting with mass effect symptoms of cranial nerve dysfunction: efficacy and imitations of endosaccular embolization with GDC. Radiat Med 2003;21:80-85

23. Schuss P, Guresir E, Berkefeld J, et al. Influence of surgical or endovascular treatment on visual symptoms caused by intracranial aneurysms: single-center series and systematic review. J Neurosurg 2011;115:694-99

24. Mattingly T, Kole MK, Nicolle D, et al. Visual outcomes for surgical treatment of large and giant carotid ophthalmic segment aneurysms: a case series utilizing retrograde suction decompression (the "Dallas technique"). J Neurosurg 2013;118:937-46

25. Park HK, Horowitz M, Jungreis C, et al. Endovascular treatment of paraclinoid aneurysms: experience with 73 patients. Neurosurgery 2003;53:14-23, discussion 24

26. Boet R, Wong GK, Poon WS, et al. Aneurysm recurrence after treatment of paraclinoid/ophthalmic segment aneurysms: a treatmentmodality assessment. Acta Neurochir (Wien) 2005;147:611-16, discussion 616

27. D’Urso PI, Karadeli HH, Kallmes DF, et al. Coiling for paraclinoid aneurysms: time to make way for flow diverters? AJNR Am J Neuroradiol 2012;33:1470-74

28. Jin SC, Kwon do H, Ahn JS, et al. Clinical and radiogical outcomes of endovascular detachable coil embolization in paraclinoid aneurysms: a 10-year experience. J Korean Neurosurg Soc 2009;45:5-10

29. Sharma BS, Kasliwal MK, Suri A, et al. Outcome following surgery for ophthalmic segment aneurysms. J Clin Neurosci 2010;17:38-42

30. Park JH, Park SK, Kim TH, et al. Anterior communicating artery aneurysm related to visual symptoms. J Korean Neurosurg Soc 2009;46:232-38 